the British Isl is, explaining the logarithmic method of plotting counts and the deductions made from the graphs.

The Archæological Section of the Union was addressed by its president, A. Cecil Piper, who discussed "The History of a Downland VillageAlfriston". He traced the development of the village from prehistoric and early historic times, proved by finds of flint and bronze implements, cinerary urns, and British and Roman coins. The Saxons had a considerable settlement, and excavation has brought to light a Saxon cemetery consisting of a hundred and twenty graves. After the Norman Conquest Alfriston came within the rape of Pevensey. Mr. Piper followed the history to the present century, mentioning its importance during the Napoleonic wars and that, at one time, the main occupation of the inhabitants was smuggling. The church was described in detail, and mention made of the Old Clergy House, the first building acquired by the National Trust, in 1896. The president of the Zoological Section, Dr. W. S. Bristowe, spoke on "The Spiders of Tslands"; he related his experiences, during collecting, on islands as far apart as the antarctic and the tropics, and explained that, broadly speaking, the number of species diminishes relatively with the area of the islands. In the unavoidable absence of Prof. J. W. H sslop-Harrison, Francis Rose addressed the Botanical Section on "The Vegetation of the Weald", treating his subject from the ecological point of view. The subject of Prof. P. Allen's presidential address to the Geological Section was "Our Chalky Heritage", in which he reviewed the present knowledge of chalk obtained by modern technique, including the electron microscope. $\mathrm{He}$ mentioned that the finest chalk in Britain is at Beachy Head, where there is practically no grit or clay and approximately 99 per cent calcium carbonate. At the time of its deposition, the water was saity, clear and more than a hundred fathoms deep, with a warmer climate prevailing than that of the present day.

G. S. Hutchings, warden of Juniper Hall Field Centre, Headley Valley, spoke on "Regional Survey and the S.-E. Union", in which, after discussing the history of the movement within the Union, he outlined proposals for the rejuvenation of the work. Although considerable investigations have been done on the classification of types of plant communities and their distribution, there is in Great Britain no general map of the distribution of types of vegetation. It would be a credit to botanical science, said Mr. Hutchings, if a map could be published showing the distribution of types of vegetation, including a classification worked out, in terms of their ecological status, of lands predominantly in agricultural or industrial use. Two Wealden transect belts were suggested by Mr. Hutchings for survey, because their northsouth orientation brings them each within a vertical column of the $2 \frac{1}{2}$-in. scale map sheets. One would be from the Thames gravel plain at Molesey via the Mole gap to the coast plain at Worthing. The other runs from the Thames inner estuary at Dartford, through the Central Weald to the South Downs and Cuckmere gap. It may be desirable to produce two distinct maps: one dealing with the physical units, geology, soil, slope, aspect and hydrology; and the other with vegetational, natural and semi-natural plant communities, life communities controlled by man, agricultural land, grazings, planted woodlands, etc.

Some very fine colour 'Kodachrome' slides of local wild-life, prepared and displayed by W. J. C. Murray, were shown by him to members of the Union. The shingle flora and fauna of the Crumbles area was studied by the botanists and ornithologists, who also visited Chailey Common and the Cuckmere Valley from Exceat bridge to the mouth of the river. The archæologists visited the historic and prehistoric sites at Wilmington and Milton Street, the castles and churches at Lewes and Pevensey and the churches at Alfriston and Westham. It is proposed to hold the next congress of the Union in Worthing during May 1953.

\section{THE TEA RESEARCH INSTITUTE OF EAST AFRICA OPENING CEREMONY}

7 HE Tea Research Institute of East Africa, the foundation and constitution of which were recorded in Nature of August 4, 1951, p. 196, was formally opened at Kericho, Kenya, on March 27 by His Excellency Sir Philip Mitchell, chairman of the East Africa High Commission and Governor of Kenya. The company assembled for the occasion included representatives of the tea industry from the three East African territories, government officials and delegates from the Tea Research Institutes in Ceylon and Nyasaland.

The ceremony was presided over by Dr. B. A. Keen, chairman of the governing body and director of the East African Agriculture and Forestry Research Organization. In welcoming the chairman of the High Commission, Dr. Keen briefly recounted the history of the new Institute and paid tribute to the foresight and initiative of the firm of Messrs. Brooke Bond and Co., Ltd., in sponsoring the affairs of the Institute during its formative period, and to the tea boards and associations whose co-operation had made the foundation possible. The Institute, he said, is the first and only research organization in

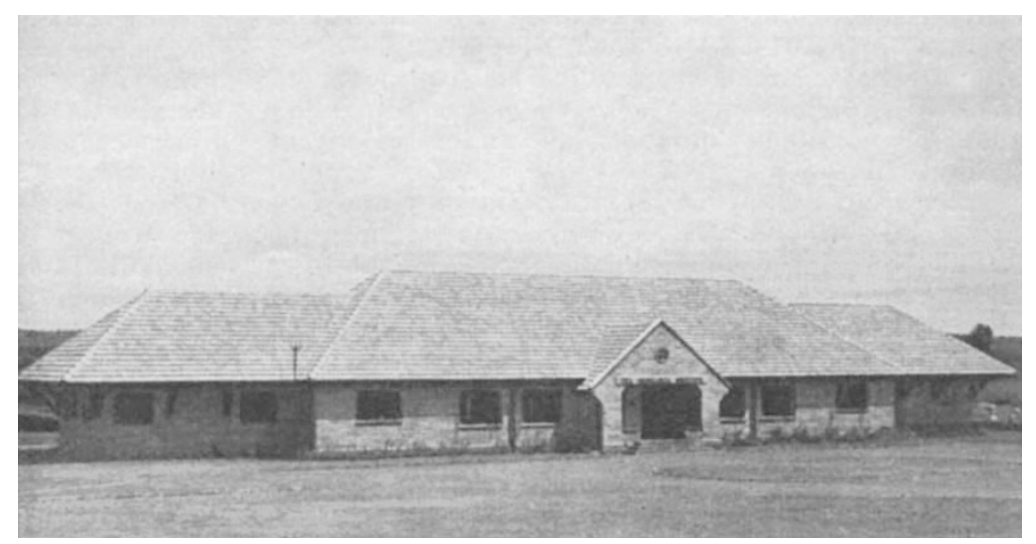

Tea Research Institute of East Africa, Kericho, Kenya 
East Africa to be conceived and established without direct financial support from government sources ; it is autonomous and receives its entire funds from the tea industry. Close and friendly liaison has been maintained between the Institute ; the East African Advisory Council for Agriculture, Animal Industry and Forestry ; the Departments of Agriculture and the East African Agriculture and Forestry Research Organization through the members of the governing body and the director.

In his reply, Sir Philip Mitchell congratulated the tea industry on the inauguration of its own research station, and particularly for having worked on an inter-territorial basis. He traced the growing importance of the tea crop in the economy of East Africa from the early stages at the turn of the nineteenth century when private enterprise in Kenya, and government enterprise at the Botanic Gardens, Entebbe, and the Amani Institute in the then German East Africa, almost simultaneously introduced the first plants of Camellia sinensis to reach East Africa. The tea industry reached a commereial basis in $192 \mathrm{I}$, and it is an expanding one. The present is therefore a very opportune time for a commodity research station to begin its work. The combination of science and practice is essential for every progressive industry; and money contributed to the support of the Institute would be in the nature of a well-spent insurance policy.

Dr. T. Eden, director of the Institute, thanked Sir Philip for formally opening the laboratories. The ceremony was followed by an inspection of the laboratories, where demonstrations and exhibits relating to the work of the Institute were on view.

\section{RECENT RESEARCH ON ELECTRICAL CONTACTS}

U

NDER the auspices of the East Midland Centre of the Institution of Electrical Engineers, a convention on "Electrical Contacts" was held at Loughborough College during April 7-9. The large attendance included members of the electrical, metallurgical and communication industries, of government research establishments and universities, as well as representation from the Netherlands, Belgium, France and Sweden. The convention was opened by Dr. W. G. Radley, engineer-in-chief of the Post Office, who stressed the important part played by contacts in modern communications: for example, in the thirty-year life of a Post Office relay the contact may operate up to $10^{2}$ times; a call between subscribers in the London area may involve 500 contacts; in the British telephone system there are altogether about 3,000 million contacts ; and failure in any of these can interrupt or distort the signal.

After Dr. L. B. Hunt (Johnson Matthey and Co., Ltd.) had outlined the requirements that must be fulfilled by a contact material, Dr. A. Fairweather (Post Office Research Station, Dollis Hill) described observations on the behaviour of contacts tarnished by exposure to the atmosphere (sulphide film on silver contacts, and oxide and carbonate film on others); what happens when film-bearing contacts are pressed together; and the properties of sliding contacts at low voltage and low mechanical pressure. A film can be broken either by high pressure or high voltage, so that the resistance of the contact depends entirely on the conditions under which it is measured; for example, a contact may have a resistance of megohms under a voltage of a millivolt, while it may be practically zero under a hundred volts. Dr. Fairweather gave detailed consideration to the change of conductance of a pair of static contacts with time due to progressive tarnishing, and indicated the effects of surface plating. Plating is not always a successful solution of the tarnish problem ; for example, a soft plating, such as gold, cannot break a tarnish film on iron-chromium. The rate of corrosion may be increased by a porous plating. Again, if the plating is hard and the substrate soft, the base may sag and the unsupported plating crack under pressure. Contact noise may be due to a moving contact bumping on and off the tract formed through the film on the other contact, and also due to the electrical breakdown of the film, which is usually the important cause ; the contact film will be repeatedly broken if, as in practice, the contact is not made at exactly the same place each time. To avoid noise, noble metals must be used. The effect of lubricating the contact with poly-tetrafluoroethylene, which forms a film that remains thin, was also considered.

Dr. A. L. Allen (Ericsson'Telephones) dealt with long life contacts for unidirectional currents of 1-20 amp. and indicated the problems found in the use of vibrator contacts. He has measured erosion craters in contact electrodes by using a 'Perspex' replica technique. His conclusion was that the use of bi-metallic contacts is not a promising method of eliminating transfer unless the number of operations is small. Experiments designed to determine contact resistance were then described : tungsten in air is covered with a high-resistance oxide film, as is chromium, but the contact resistance falls when the contacts operate in a rare-gas atmosphere. Dr. Allen concluded that mechanical wear of contacts is insignificant compared with electrical wear ; copperpalladium has a low rate of transfer; and the search for new alloys is not a promising solution. $\mathrm{He}$ suggested the elimination of transfer by installing parallel circuits to prevent the contact voltage rising above the boiling voltage.

Miss J. Warham (Electrical Research Association) described the effect of inductance on fine transfer between platinum contacts in a $6-\mathrm{V}$. circuit with currents of the order of $1 \mathrm{amp}$. and controlled circuit inductance of $0 \cdot 05-10 \mu \mathrm{H}$. Transfer is measured by optical examination of the pips formed on the cathode after a large number $\left(10^{5}\right)$ of operations. The results show that there is a residual transfer at break which is independent of the circuit inductance. This is bridge transfer, which can be explained by the Thomson effect in accordance with Davidson's formula for the shift of the hottest cross-section. Transfer is dependent on inductance when this is greater than $0.3 \mu \mathrm{H}$., and this is attributed to a short are.

Dr. P. M. Davidson (Physics Department, University College of Swansea) outlined the results of calculations which trace in detail the changes in the micro-geometry of the successive stages in the separation of two electrodes. The succession of shapes assumed by a liquid bridge under the action of surface tension includes nodoid shapes and unduloid shapes, of which the cylinder is a particular case. The particular form will depend on the properties of the particular metal (such as the variation of specific resistance with temperature) and how the current changes as the contact potential increases. Slides illustrating the computed results in typical cases were shown. The 